\title{
Analysis on the Image of Female College Students Represented by the Network Media from the Perspective of Communication
}

\author{
Yang Xie \\ Xiamen University Tan Kah Kee College \\ Xiamen, China
}

\author{
Jing $\mathrm{Wu}^{*}$ \\ Xiamen University Tan Kah Kee College \\ Xiamen, China \\ *Corresponding author
}

\begin{abstract}
The media image of female college students is the reconstruction of objective reality through media coverage, which is a "mock reality" presenting in the public mind. With the commercialization of online media and the fragmented reading habits of the target people, the reports on female college students in online media tend to achieve the eye effect, and the related news headlines tend to present negative and extreme individual cases. At the same time, the female college students' loss of power of long-term discourse results in their negative and weak image in online media. Starting from the theoretical background of agenda setting and media image under the perspective of communication study, this passage tries to conduct the content analysis of the titles of $\mathbf{1 1}$ media of four types: web portals, mainstream news sources, terminal news sources and forum communities in three months, so that they can explore the female college student image which reconstruct through simulated reality in the news report of China's Internet media. In addition, this paper gives appropriate advice and countermeasures of how to reshape the network image of female college students through the reason analysis from the perspective of female college student aphasia, media management system, Internet media features and so on.
\end{abstract}

Keywords—agenda setting; media image; online media; female college student; content analysis

\section{INTRODUCTION}

\section{A. Questions Raising}

In 1972, through empirical research, Malcolm Macmus and Donald Shaw proposed that the prominent report of some events and social is sues by the mass media in certain stage causes widespread and common concern and attention, and thus becomes the central topic of social discussion. According to their theory, it is considered that the factors, such as the contact frequency of public and media, the needing degree of public for the media, situation of interpersonal communication and interests of different public will affect the effectiveness of agenda setting in the process of setting.

Although some scholars pointed out that with the audiences' increasing initiative in the new media, the traditional agenda setting has the trend to be transformed into "self-setting". However, online media also has the function of setting an agenda for other traditional media. That is to say, online media guides the direction of public opinion in a certain degree and thus forms various hot issues, resulting a large number of reports from traditional media.

\section{B. Internet Media Features}

With the emerging of online media, the new media represented by mobile media and online media has been listed in the mainstream media. In order to seek the eye effect, audiences' attention and activity has become media's seeking purpose. In contrast with the role definition of women intellectuals, the media tend to use some key words that can attract attention. The reports on female college students are inundated with negative words, such as naked loan, being kept as a mistress, shallowness and prostitution. How do the media shape the image of female college students? Is there a deviation between the media image of "female college students" and the real female college students? These features forge a bond between "media image" and "female college students".

\section{Media Image}

Li Puman believes that in the modern society where the mass media is unprecedentedly developed, people's thought and behavior are influenced by three kinds of "reality": first, the "objective reality" that one can directly feel; second, the "Symbolic Reality (Mimicry Reality)" that is selectively promoted by media; third, "Subjective Reality", which is "Image of the Outside World" in our mind. Therefore, in the real society, the objective facts that we know are not always the real objective world, but the reconstruction of the objective reality through the media report and a "mock reality" presenting in the public mind. The cognitive process is often influenced by media features, media tendencies, journalistic subjective cognitions or attitudes, and it deviates from the real objective world. Besides, the choice of media will greatly affect the audience's cognition of social awareness.

Both "female" and "college student" have attention rate by their role, while the female college students are more news worthy than the other social groups because of their dual roles. The female college student's media image refers to the public image presented by the media. Therefore, the media 
coverage of female college students will largely determine the public's perception of female college students. The content analys is of female college students in media reports can reflect the "objective image" that the public contact, which has important practical significance.

\section{Existing Research}

Domestic scholars have few studies on the media images of college students. Cai Yueliang, in his article The Media Demonizes the Image of College Students, made a analysis on three metropolitan newspapers and online medias to draw the conclusion that the media images of the college students displayed by the mass media are some negatives: over-opening of sexual concept and indulgence, violence and murder, apathetic and sophisticated manner and low quality ... The elite image of college students is being decomposed. Zhang Zhigang and Wang Beibei, in the paper of Misreading of the Media on the Image of Female Colleges Students, made a statistical analysis on the fully annual report of female college students by the Sina in 2011 to find that: the reports on positive image are only 50 articles, accounting for $13.6 \%$ of the total reports; the reports on negative images purposed for curiouse, such as suicide, sexuality and crime, deceit, are 216 articles, accounting for $58.9 \%$ of the total reports; other relatively objective and neutral reports without obvious gender-based discrimination, are 101 articles, accounting for $27.5 \%$ of the total reports. And they also inevitably involve the gender characteristics of female college students and the concepts of materialis $m$ contrary to the mainstream of social values. It can be seen that negative news occupies an absolutely dominant position. Female college students are almost shaped by the media as an alienated group and are expelled from the mainstream of the community.

\section{RESEARCH METHODS}

This paper takes the news headlines related to female college students in online media as research objects and use a qualitative research method to make analysis on the collected materials. First of all, in the selection of online media, this study selected Tencent, Sina, Netease, Sohu (web portal), News Network, PhoenixNet, People's Network (mainstream news source), WeChat, MicroBlog (terminal information source), Skyline, MOP (foru m community) as sample objects, totaling 11 media. For selection of the web portals, it referred to the Ranking of the Top 100 Most Visited Websites in China in 2016, and such webs ranking is not authoritative, so author refered to a number of leaderboards and extracts the top ten webs such as Tencent, Sohu and Netease and Sina, as the information website representative. For the mainstream of news source, it selected the official media such as Xinhua Net, People's Network and the PhoenixNet which is authoritative among the non-official media. It covers four media types, including web portals, major online forums, mainstream official sources of information (traditional media digitization), and terminal messaging (with high coverage and activeness), with a comprehensive representation. Secondly, the sampling time is June 1, 2017, and the samples are taken in the last three months (March 1, 2017 - May 31, 2017). Finally, for collection of the textual data, "female college students" is searched as the key words, and according to the search engine (relevancy), if there are headlines with same expression, the repetition is deduced, and the top 20 headlines are selected, and then the base of 220 samples is got. This article mainly studies the analysis on the images of domestic female college students reproduced by the media, so it excludes the related titles of the image of foreign college graduates, such as "Indian scientist who was arrested in the United States for becoming suspected of harassing female college students claimed he liked the student", "Japan selected the most beautiful female college students and the most handsome male college students in 2017" and others. Finally, 205 valid samples are obtained and clas sified.

\section{RESEARCH RESULTS}

\section{A. Horizontal Research}

With a high active topic about female college students, high topic repetition rate and high concentration ratio of headlines, the agenda setting still plays an important role.

Sample analysis found that in the web portal and terminal information source media, all the issues of female college students are reported in the news of the recently last month according to the sequence of data push of default relevance, which indicate the issue of female college students has a large number, high activity and timely information updates.

At the same time, the author interprets the content of the titles and extracts the key words of the title, to find that the cross-media repetition rate of synonymous key information is $43 \%$. In the independent media, the repetition rate of same topics is $83 \%, 42 \%$ and $40 \%$ respectively in Tencent, Sohu and Skyline. As shown in "Table I", in terms of the title content, the samples related to life experience have the highest proportion, accounting for about 45\%; the topics on life experiences and on personal and property security basically take near $80 \%$ of the total; the topics mainly related to vocation and learning of female college students only accounts for about $4 \%$, which reflect that the media tend to choose the topics on curious and confidence, sensitive and in-depth private topic or the topics on image of the victim. Both in terms of keywords and topic categories, they all show a strong concentration.

TABLE I. TOPIC ClASSIFICATION OF SAMPLE TITLES

\begin{tabular}{|l|l|l|}
\hline \multicolumn{1}{|c|}{ Topic classification } & The number of titles & Proportion \\
\hline Life experience & 93 & $45.4 \%$ \\
\hline Employment & 29 & $14.1 \%$ \\
\hline Learning & 8 & $3.9 \%$ \\
\hline Emotion & 6 & $2.9 \%$ \\
\hline Personal and property security & 68 & $33.2 \%$ \\
\hline Total & 205 & $100.0 \%$ \\
\hline
\end{tabular}

Under the influence of attention economy, in order to maximally attract the audience's attention, the media will spontaneously converge and repeat the "eye-catching" issue, and such tendency works on the audience by reaction, that is, the information received by the audience is centralized and single. Therefore, the is sue setting still plays an important role in reproduction of the image of the reported object. In the total 
93 samples of life experiences, 14 are positive headings, 20 are neutral headings, and 59 are negative headings. In the total 68 samples of personal and property security, 63 are negative headings, most of which are images of "the victims and the weak" (53). Compared with the academic and active spirit of female college students, the audience seems to pay more attention to the information such as "from nude loan to selling ovum, female college student do not jump in the pit". Even the positive heading in the samples, most of them have the content of life, such as beauty, Goddess, artificial respiration and so on.

\section{B. Vertical Contrast}

Compared with the previous media reports on the images of Chinese female college students, the following research conclusions have been analyzed and verified by the contents:

- In terms of image reproduction, the negative media coverage still shows the mainstream trend, and the proportion continues to rise;

- In terms of the content reported, "learning" is still the weak area, with little attention by the media, and the key words such as "body" and "personal" of female college students have become the hot topics in the media.

- During the reproduction of the negative image of female college students, the image of "the victims and the weak" is spread, giving the audience the stiff impression of being weak, vulnerable, easily deceived, suffering from diseases and sexually open.

Compared with the existing research, the content analysis and research have some changes as followings:

- The existing research findings confirm that there are more positive reports on female college students in the traditional media or the official media, but more negative reports on female college students in the online media. From the sampling, it is found that in 20 samples of Xinhua Online, the negative titles are 9, positive titles are 7 , and the neutral titles are 4 . To a certain extent, it reflects the media further enlarges the reproduction of the negative image of female college students.

- It is shown by some research that female college students appears in the image of "the victims and the bedeman" in the largest proportion in the media. Although the results of the sample survey still maintain the largest proportion about $40 \%$, female college students as the subjects of negative images also take a relatively high proportion that is $23 \%$. Combined with the viewpoints mentioned above in this article, the audience is more willing to read or dispel the contrast image that is not consistent with the intrinsic cognition of female college students, which is easier for the public to snoop and hunt their curiosity. The negative stiff image of female college students has formed, so the audiences accept the weak image of female students as the victims and the bedman to a certain extent. Therefore, the subject of a negative image can meet the contrast of image to some extent.

\section{CONCLUSION}

First of all, under the influence of attention economy, the market framework and survival pattern of online media rely on audiences' clicks or mass flow rate, which can directly affect the media's income. Just because of this, in order to meet the audience's curiosity and their snooping psychology, the various topics and events of female college students have been drawn in a shadow to people's attention by the media.

Second, in the above network media market framework, news also tends to entertainment in the news report and dissemination in recent years. Especially for the development of new media, on the one hand, We Media has made it possible for everybody to give their voice, and the chances of any public opinion news causing cyber-violence have risen; on the other hand, due to the eyeball effect, the operating capacity and the marketization go beyond the credibility of news, and how to attract the audience under the premise of objective and fair reports of internet media is a question worthy of further discussion. Meanwhile, for a long time, female college students as the object of reporting, the discourse is manipulated by the media, without their own voice. Some groups of the media have been correcting the image of female college students, but it is difficult to form a positive force with high credibility due to lack of the endorsement of authoritative agencies and organizations.

Finally, the current public has an uneven media quality, of which the public with bad media quality cannot discern the differences between the media information and the objective reality, so they often transfer the negative image of female college students reproduced by the media to the entire group of female college students from individually to fully.

Based on the above analysis, the following suggestions are put forward: First, to establish a sense of responsibility among the media, strengthen the supervision under the marketoriented mechanism, and restore the objective, truthful and notarized media coverage. Second, to enhance the public media literacy, increase the discourse power and make the audience have sufficient capacity for information identification; third, increase the liberation of the voice of female college students, make them participate in the digital existence, and enhance the group's initiative. Positive reports should also be "eye-catching." Let the positive image of female students release through specific channels in an effective way, large scale and rich content.

\section{REFERENCES}

[1] (US) Walter Lippmann. Public Opinion [M] Beijing: Huaxia Publishing House 1989

[2] Guo Qingguang. Tutorial of Communication Sciences[M]. Beijing: China Renmin University Press. 1999

[3] Ge Lin. Research on the Media Image of Contemporary Female College Students [J], Journalism and Communication, 2011.7,139-140

[4] Li Zhongjun. Interaction and Integration of New Media and Traditional Media [J], Academic Exchange, 2010 (5): 205-207 
[5] Malcolm McKenzie Donald Shaw. The Functions of Mass Communication Agenda Setting [J], Opinion Quarterly, 1972

[6] Miao Haiyang. From Media Agenda Setting to Audience Self-Setting[J], New Characteristics of Net work Media Agenda Setting Theory, 2011,13 (6): $30-33$

[7] Shu Huan. The Image Presentation of Female College Students in the Media - Taking 2009 "People's Daily" and "Chinese Business Daily" as examples[J], News World, 2011 (1), 1301-132

[8] Lei Xiaoyan. Content Analysis of Online Media on the Image of Female College Students [J]. Hua Zhang, 2007 (12)

[9] Zhang Zhigang, Wang Beibei. Media Misunderstanding of the Image of Female College Students[J], Contemporary Youth Research, 2013 (7): 71-76

[10] "The 38th Statistical Report on the Internet Development in China". China Internet Network Information Center (CNNIC). Http://www.cnnic.cn. January 2011. 